\title{
ADCSS-Labeling of 2-Tuple Graphs of Some Graphs
}

\author{
Dr. Mathew Varkey $T K^{*}$ and Sunoj $B S^{* *}$ \\ *Department of Mathematics, $T$ K M College of Engineering , Kollam 5 \\ **Department of Mathematics, Government Polytechnic College, Attingal
}

\begin{abstract}
A graph labeling is an assignment of integers to the vertices or edges or both subject to certain conditions. In this paper, we introduce the new concept, an absolute difference of cubic and square sum labeling of a graph. The graph for which every edge label is the absolute difference of the sum of the cubes of the end vertices and the sum of the squares of the end vertices. It is also observed that the weights of the edges are found to be multiples of 2. Here we characterize 2-tuple graphs of middle graph of paths and cycles, crown graph, star graphs, the triangular snake graph, quadrilateral snake graph for adcss labeling.
\end{abstract}

Keywords: Graph labeling, sum square graph, square sum graphs, cubic graphs, middle graphs, 2-tuple graph.

\section{Introduction}

All graphs in this paper are finite and undirected. The symbol $V(G)$ and $E(G)$ denotes the vertex set and edge set of a graph G. The graph whose cardinality of the vertex set is called the order of G, denoted by $p$ and the cardinality of the edge set is called the size of the graph $\mathrm{G}$, denoted by q. A graph with p vertices and $q$ edges is called a (p,q)- graph.

A graph labeling is an assignment of integers to the vertices or edges. Some basic notations and definitions are taken from [1], [2], ,3] , [4] and [5]. Some basic concepts are taken from Frank Harary [2]. We introduced the new concept, an absolute difference of cubic and square sum labeling of a graph [6]. In [6],[7],[8],[9],[10],[11] , it is shown that planar grid, web graph, kayak paddle graph, snake graphs, friendship graph, armed crown, fan graph, cycle graphs, wheel graph etc have an adcss labeling. In this paper we investigated ADCSS labeling of some 2-tuple graphs.

Definition: 1.1 [6]Let $G=(V(G), E(G))$ be a graph. A graph $G$ is said to be absolute difference of the sum of the cubes of the vertices and the sum of the squares of the vertices, if there exist a bijection

$\mathrm{f}: \mathrm{V}(\mathrm{G}) \rightarrow\{1,2,----------, p\}$ such that the induced function $f_{\text {adcss }}^{*}: \mathrm{E}(\mathrm{G}) \rightarrow$ multiples of 2 is given by $f_{\text {adcss }}^{*}(\mathrm{uv})=\left|\left(\mathrm{f}(\mathrm{u})^{3}+\mathrm{f}(\mathrm{v})^{3}\right)-\left(\mathrm{f}(\mathrm{u})^{2}+\mathrm{f}(\mathrm{v})^{2}\right)\right|$ is injective.

Definition: 1.2 A graph in which every edge associates distinct values with multiples of 2 is called the sum of the cubes of the vertices and the sum of the squares of the vertices. Such a labeling is called an absolute difference of cubic and square sum labeling or an absolute difference css-labeling.

\section{Main Results}

Definition 2.1 Let $V(G)$ and $X(G)$ denote the vertex set and the edge set of $G$, respectively. The middle graph $M(G)$ of $G$ whose vertex set is $V(G)$ union $X(G)$ where two vertices are adjacent if and only if

(i) They are adjacent edges of $\mathrm{G}$ or

(ii) One is a vertex and other is an edge incident with it.

Definition 2.2 The crown graph $\mathrm{Cr}_{\mathrm{n}}$ is obtained by joining a pendant edge to each vertex of cycle $\mathrm{C}_{\mathrm{n}}$.

Definition 2.3 The triangular snake graph $T_{n}$ is obtained from the path $P_{n}$ by replacing each edge $v_{i} v_{i+1}$ by cycle $\mathrm{C}_{3}\left(\mathrm{v}_{\mathrm{i}} \mathrm{u}_{\mathrm{i}} \mathrm{v}_{\mathrm{i}+1}\right)$ for $1 \leq \mathrm{i} \leq \mathrm{n}-1$.

Definition 2.4 The quadrilateral snake graph $Q_{n}$ is obtained from the path $P_{n}$ by replacing each edge $v_{i} v_{i+1}$ by cycle $\mathrm{C}_{4}\left(\mathrm{v}_{\mathrm{i}} \mathrm{u}_{\mathrm{i}} \mathrm{u}_{\mathrm{i}+1} \mathrm{v}_{\mathrm{i}+1}\right)$ for $1 \leq \mathrm{i} \leq \mathrm{n}-1$

Definition 2.5 Let $G=(V, E)$ be a simple graph and $G^{\prime}=\left(V^{\prime}, E^{\prime}\right)$ be another copy of graph $G$. Join each vertex $v$ of $\mathrm{G}$ to the corresponding vertex v' of G' by an edge. The new graph thus obtained is the 2- tuple graph of G. 2tuple graph of $\mathrm{G}$ is denoted by $\mathrm{T}^{2}(\mathrm{G})$. Further if $\mathrm{G}=(\mathrm{p} ; \mathrm{q})$ then $\left|\mathrm{V}\left\{\mathrm{T}^{2}(\mathrm{G})\right\}\right|=2 \mathrm{p}$ and $\quad\left|\mathrm{E}\left\{\mathrm{T}^{2}(\mathrm{G})\right\}\right|=2 \mathrm{q}+\mathrm{p}$

Theorem: 2.1 2-tuple graph of the middle graph of path $P_{n}, T^{2}\left\{M\left(P_{n}\right)\right\}$ admits ADCSS - labeling.

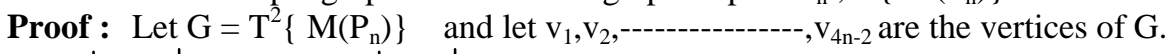

Here $|\mathrm{V}(\mathrm{G})|=4 \mathrm{n}-2$ and $|\mathrm{E}(\mathrm{G})|=8 \mathrm{n}-9$

Define a function $\mathrm{f}: \mathrm{V} \rightarrow\{1,2,3,--------, 4 \mathrm{n}-2\}$ by $\mathrm{f}\left(\mathrm{v}_{\mathrm{i}}\right)=\mathrm{i}, \mathrm{i}=1,2,-----, 4 \mathrm{n}-2$.

For the vertex labeling $\mathrm{f}$, the induced edge labeling $f_{\text {adcss }}^{*}$ is defined as follows
$f_{\text {adcss }}^{*}\left(v_{i} v_{i+1}\right)$
$=(\mathrm{i}+1)^{2} \mathrm{i}+\mathrm{i}^{2}(\mathrm{i}-1)$,
$\mathrm{i}=1,2,3,----------, 4 n-3$
$f_{\text {adcss }}^{*}\left(v_{2 i} v_{2 i+2}\right)$
$=(2 \mathrm{i}+2)^{2}(2 \mathrm{i}+1)+(2 \mathrm{i})^{2}(2 \mathrm{i}-1)$,
$\mathrm{i}=1,2,3,---------\cdot \mathrm{n}-2$. 
$f_{\text {adcss }}^{*}\left(v_{2 i+1} v_{4 n-2-2 i}\right)=(2 \mathrm{i}+1)^{2}(2 \mathrm{i})+(4 \mathrm{n}-2-2 \mathrm{i})^{2}(4 \mathrm{n}-3-2 \mathrm{i})$,

$f_{\text {adcss }}^{*}\left(v_{2 i+2} v_{4 n-3-2 i}\right)=(2 \mathrm{i}+2)^{2}(2 \mathrm{i}+1)+(4 \mathrm{n}-3-2 \mathrm{i})^{2}(4 \mathrm{n}-4-2 \mathrm{i})$,

$f_{\text {adcss }}^{*}\left(v_{2 n-1+2 i} v_{2 n+1+2 i}\right)=(2 \mathrm{n}-1+2 \mathrm{i})^{2}(2 \mathrm{n}-2+2 \mathrm{i})+(2 \mathrm{n}+1+2 \mathrm{i})^{2}(2 \mathrm{n}+2 \mathrm{i})$,

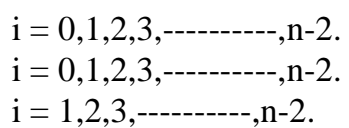

All edge values of $\mathrm{G}$ are distinct, which are multiples of 2.That is the edge values of $\mathrm{G}$ are in the form of an increasing order. Hence $\mathrm{T}^{2}\left\{\mathrm{M}\left(\mathrm{P}_{\mathrm{n}}\right)\right\}$ admits adcss-labeling.

Example 2.1 ADCSS labeling of the graph $\mathrm{T}^{2}\left\{\mathrm{M}\left(\mathrm{P}_{4}\right)\right\}$ is shown in figure (i)

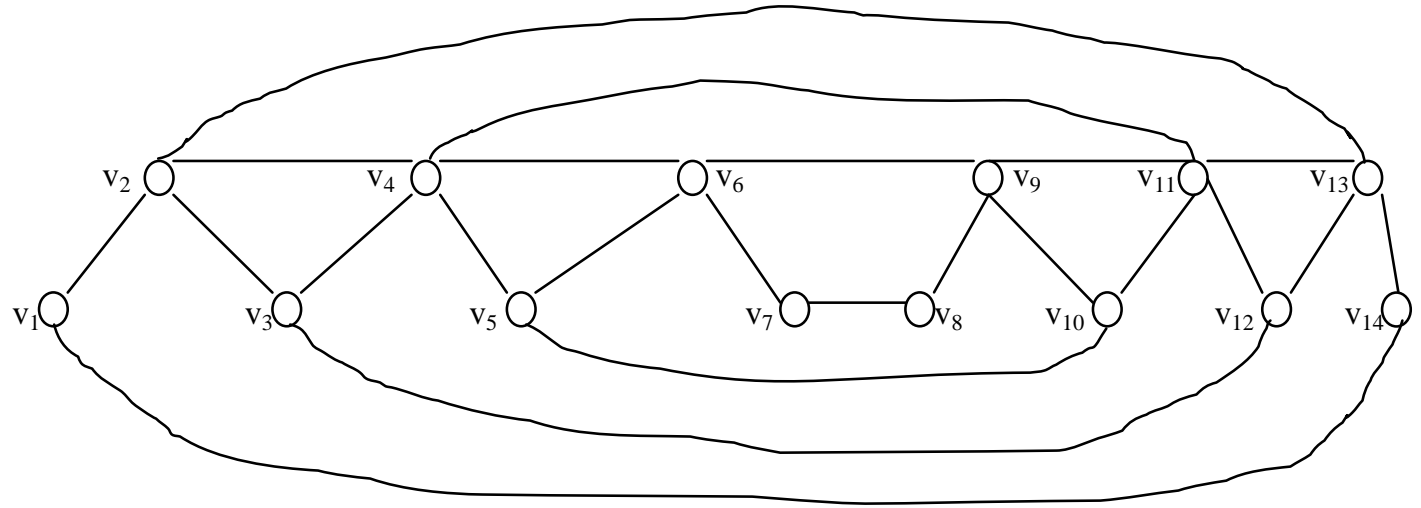

fig - i

Theorem: 2.2 2-tuple graph of the middle graph of cycle $C_{n}, T^{2} M\left(C_{n}\right)$ admits ADCSS - labeling.

Proof : Let $G=T^{2} M\left(C_{n}\right)$ and let $v_{1}, v_{2},---------------, v_{4 n}$ are the vertices of $G$.

Here $|\mathrm{V}(\mathrm{G})|=4 \mathrm{n}$ and $|\mathrm{E}(\mathrm{G})|=8 \mathrm{n}$

Define a function $\mathrm{f}: \mathrm{V} \rightarrow\{1,2,3,-------, 4 \mathrm{n}\}$ by $\mathrm{f}\left(\mathrm{v}_{\mathrm{i}}\right)=\mathrm{i}, \mathrm{i}=1,2,------, 4 \mathrm{n}$.

For the vertex labeling $\mathrm{f}$, the induced edge labeling $f_{\text {adcss }}^{*}$ is defined as follows

$\begin{array}{rlrl}f_{a d c s s}^{*}\left(v_{i} v_{i+1}\right) & =(\mathrm{i}+1)^{2} \mathrm{i}+\mathrm{i}^{2}(\mathrm{i}-1), & \mathrm{i}=1,2,----, 2 \mathrm{n}-1,2 \mathrm{n}+1,----, 4 \mathrm{n}-1 \\ f_{a d c s s}^{*}\left(v_{2 i} v_{2 i+2}\right) & =(2 \mathrm{i}+2)^{2}(2 \mathrm{i}+1)+(2 \mathrm{i})^{2}(2 \mathrm{i}-1), & & \\ f_{a d c s s}^{*}\left(v_{2} v_{2 n}\right) & =(2 \mathrm{n})^{2}(2 \mathrm{n}-1)+4 & \\ f_{a d c s s}^{*}\left(v_{1} v_{2 n}\right) & =(2 \mathrm{n})^{2}(2 \mathrm{n}-1) & \\ f_{a d c s s}^{*}\left(v_{2 n+2} v_{4 n}\right) & =(2 \mathrm{n}+2)^{2}(2 \mathrm{n}+1)+(4 \mathrm{n})^{2}(4 \mathrm{n}-1) & \\ f_{a d c s s}^{*}\left(v_{2 n+1} v_{4 n}\right) & =(2 \mathrm{n}+1)^{2}(2 \mathrm{n})+(4 \mathrm{n})^{2}(4 \mathrm{n}-1) & \\ f_{a d c s s}^{*}\left(v_{2 n+2 i} v_{2 n+2 i+2}\right) & =(2 \mathrm{n}+2 \mathrm{i})^{2}(2 \mathrm{n}+2 \mathrm{i}-1)+(2 \mathrm{n}+2 \mathrm{i}+2)^{2}(2 \mathrm{n}+2 \mathrm{i}+1), & \mathrm{i}=1,2,---------------, \mathrm{n}-1 . \\ f_{a d c s s}^{*}\left(v_{i} v_{2 n+i}\right) & =(\mathrm{i})^{2}(\mathrm{i}-1)+(2 \mathrm{n}+\mathrm{i})^{2}(2 \mathrm{n}), & \mathrm{i}=1,2,-----------, 2 \mathrm{n}\end{array}$

All edge values of $\mathrm{G}$ are distinct, which are multiples of 2.That is the edge values of $\mathrm{G}$ are in the form of an increasing order. Hence $T^{2} M\left(C_{n}\right)$ admits adcss-labeling.

Example : 2.2 ADCSS labeling of the graph $T^{2}\left\{M\left(C_{3}\right)\right\}$ is shown in figure (ii)

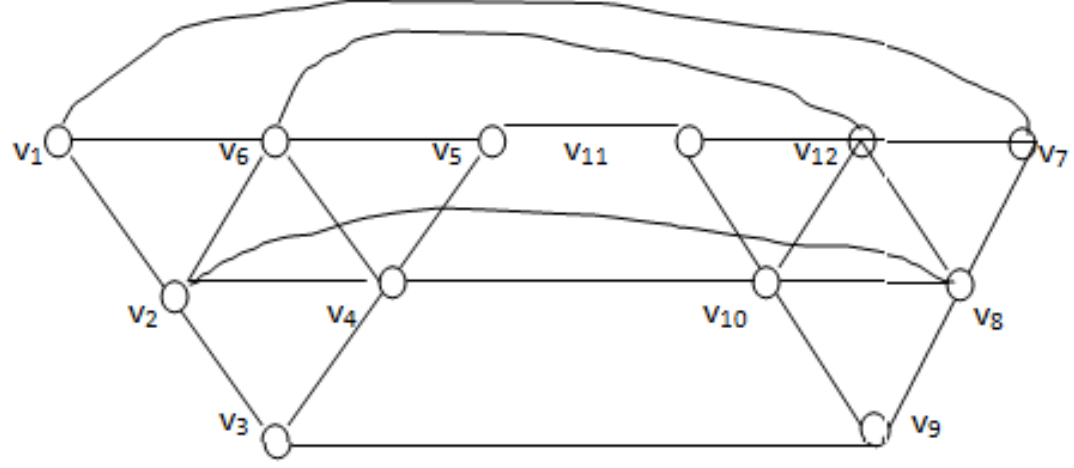

fig - ii

Theorem: $2.3 \mathrm{~T}^{2}\left(\mathrm{Cr}_{\mathrm{n}}\right)$ admits ADCSS - labeling.

Proof : Let $\mathrm{G}=\mathrm{T}^{2}\left(\mathrm{Cr}_{\mathrm{n}}\right)$ and let $\mathrm{v}_{1}, \mathrm{v}_{2},------------, \mathrm{v}_{4 \mathrm{n}}$ are the vertices of $\mathrm{G}$.

Here $|\mathrm{V}(\mathrm{G})|=4 \mathrm{n}$ and $|\mathrm{E}(\mathrm{G})|=6 \mathrm{n}$

Define a function $\mathrm{f}: \mathrm{V} \rightarrow\{1,2,3,-------, 4 \mathrm{n}\}$ by 
$\mathrm{f}\left(\mathrm{v}_{\mathrm{i}}\right)=\mathrm{i}, \mathrm{i}=1,2,-----, 4 \mathrm{n}$.

For the vertex labeling $\mathrm{f}$, the induced edge labeling $f_{a d c s s}^{*}$ is defined as follows
$f_{\text {adcss }}^{*}\left(v_{i} v_{i+1}\right) \quad=\mathrm{i}^{2}(\mathrm{i}-1)+(\mathrm{i}+1)^{2} \mathrm{i}$,
$f_{\text {adcss }}^{*}\left(v_{i} v_{i+n}\right) \quad=(\mathrm{i}+\mathrm{n})^{2}(\mathrm{i}+\mathrm{n}-1)+(\mathrm{i})^{2}(\mathrm{i}-1)$,
$\mathrm{i}=1,2,-----, \mathrm{n}-1, \mathrm{n}+1$, $-, 2 n-1$.
$f_{\text {adcss }}^{*}\left(v_{n} v_{1}\right)$
$=(\mathrm{n})^{2}(\mathrm{n}-1)$
$\mathrm{i}=1,2,3,----\cdot-$
$f_{\text {adcss }}^{*}\left(v_{n+1} v_{2 n}\right)=(\mathrm{n}+1)^{2}(\mathrm{n})+(2 \mathrm{n})^{2}(2 \mathrm{n}-1)$
$f_{\text {adcss }}^{*}\left(v_{2 n+i} v_{i}\right) \quad=(\mathrm{i})^{2}(\mathrm{i}-1)+(2 \mathrm{n}+\mathrm{i})^{2}(2 \mathrm{n}+\mathrm{i}-1), \quad \mathrm{i}=1,2,---------, \mathrm{n}$
$f_{\text {adcss }}^{*}\left(v_{2 n+i} v_{3 n+i}\right)=(3 \mathrm{n}+\mathrm{i})^{2}(3 \mathrm{n}+\mathrm{i}-1)+(2 \mathrm{n}+\mathrm{i})^{2}(2 \mathrm{n}+\mathrm{i}-1), \quad \mathrm{i}=1,2,---------, \mathrm{n}$
$f_{\text {adcss }}^{*}\left(v_{n+i} v_{3 n+i}\right)=(\mathrm{n}+\mathrm{i})^{2}(\mathrm{n}+\mathrm{i}-1)+(3 \mathrm{n}+\mathrm{i})^{2}(3 \mathrm{n}+\mathrm{i}-1), \quad \mathrm{i}=1,2,-\cdots$

All edge values of $\mathrm{G}$ are distinct, which are multiples of 2.That is the edge values of $\mathrm{G}$ are in the form of an increasing order. Hence $\mathrm{T}^{2}\left(\mathrm{Cr}_{\mathrm{n}}\right)$ admits adcss-labeling.

Example 2.3 ADCSS labeling of the graph $\mathrm{T}^{2}\left(\mathrm{Cr}_{4}\right)$ is shown in figure (iii)

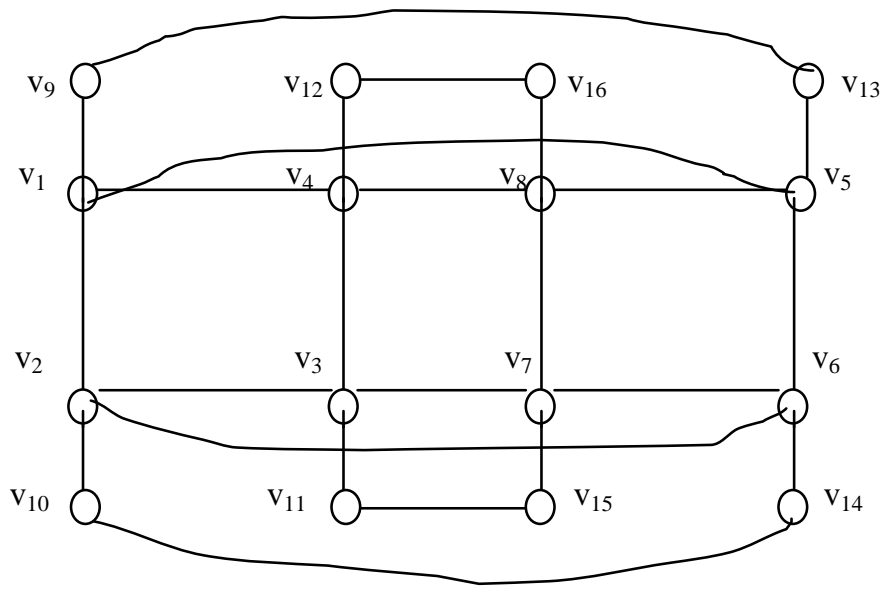

fig - iii

Theorem: $2.4 \mathrm{~T}^{2}\left(\mathrm{~K}_{1, \mathrm{n}}\right)$ admits ADCSS - labeling, where $\mathrm{K}_{1, \mathrm{n}}$ is the star graph.

Proof : Let $G=T^{2}\left(K_{1, n}\right)$ and let $v_{1}, v_{2},----------v_{2 n+2}$ are the vertices of $G$.

Here $|\mathrm{V}(\mathrm{G})|=2 \mathrm{n}+2$ and $|\mathrm{E}(\mathrm{G})|=3 \mathrm{n}+1$

Define a function $\mathrm{f}: \mathrm{V} \rightarrow\{1,2,3,-------, 2 \mathrm{n}+2\}$ by

$$
f\left(v_{i}\right)=i, i=1,2,-----, 2 n+2 \text {. }
$$

For the vertex labeling $\mathrm{f}$, the induced edge labeling $f_{a d c s s}^{*}$ is defined as follows
$f_{a d c s s}^{*}\left(v_{1} v_{i+1}\right)$
$=(i+1)^{2} \mathrm{i}$,
$\mathrm{i}=1,2,-\cdots---\cdots$
$f_{\text {adcss }}^{*}\left(v_{n+2} v_{n+2+i}\right)$
$=(\mathrm{n}+2)^{2}(\mathrm{n}+1)+(\mathrm{n}+2+\mathrm{i})^{2}(\mathrm{n}+1+\mathrm{i})$,
$\mathrm{i}=1,2,3,--------$, n.

$f_{\text {adcss }}^{*}\left(v_{i} v_{n+i+1}\right) \quad(\mathrm{i})^{2}(\mathrm{i}-1)+(\mathrm{n}+\mathrm{i}+1)^{2}(\mathrm{n}+\mathrm{i})$,
All edge values of $\mathrm{G}$ are distinct, which are multiples of 2.That is the edge values of $\mathrm{G}$ are in the form of an

$\begin{array}{ccc}f_{a d c s s}^{*}\left(v_{i} v_{n+i+1}\right) & =(\mathrm{i})^{2}(\mathrm{i}-1)+(\mathrm{n}+\mathrm{i}+1)^{2}(\mathrm{n}+\mathrm{i}), & \mathrm{i}=1,2,3,-------, \mathrm{n}+1 . \\ \text { All edge values of } \mathrm{G} \text { are distinct, which are multiples of } 2 \text {.That is the edge values of } \mathrm{G} \text { are in the form of an }\end{array}$ increasing order. Hence $\mathrm{T}^{2}\left(\mathrm{~K}_{1, \mathrm{n}}\right)$ admits adcss-labeling.

Example 2.4 ADCSS labeling of the graph $\mathrm{T}^{2}\left(\mathrm{~K}_{1,4}\right)$ is shown in figure (iv)

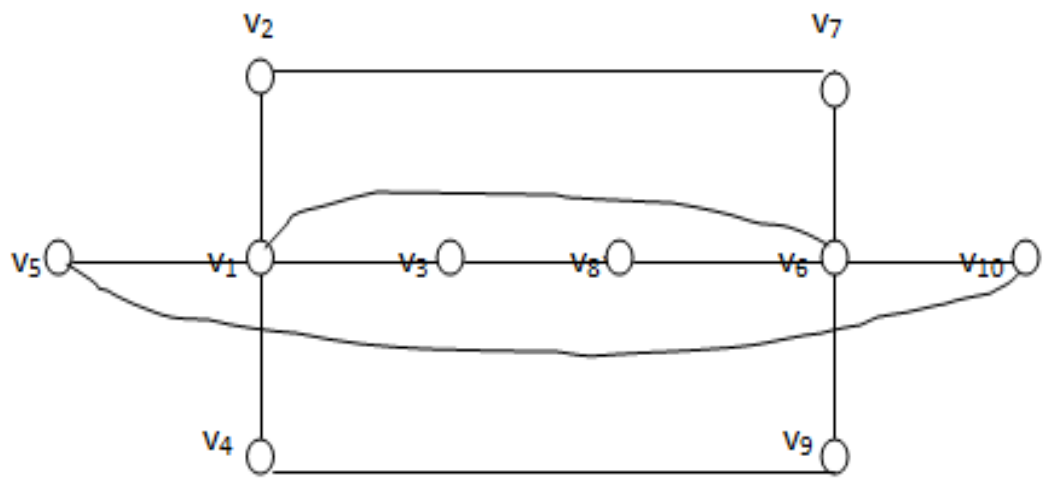

fig - iv

Theorem: $2.5 \mathrm{~T}^{2}\left(\mathrm{~T}_{\mathrm{n}}\right)$ admits ADCSS - labeling, where $\mathrm{T}_{\mathrm{n}}$ is the triangular snake graph

Proof : Let $G=T^{2}\left(T_{n}\right)$ and let $v_{1}, v_{2},-----------, v_{4 n-2}$ are the vertices of $G$. 
Here $|\mathrm{V}(\mathrm{G})|=4 \mathrm{n}-2$ and $|\mathrm{E}(\mathrm{G})|=8 \mathrm{n}-7$

Define a function $\mathrm{f}: \mathrm{V} \rightarrow\{1,2,3,-------, 4 \mathrm{n}-2\}$ by

$f\left(v_{i}\right)=i, i=1,2,-----, 4 n-2$.

For the vertex labeling $\mathrm{f}$, the induced edge labeling $f_{\text {adcss }}^{*}$ is defined as follows
$f_{\text {adcss }}^{*}\left(v_{i} v_{i+1}\right) \quad=(\mathrm{i}+1)^{2} \mathrm{i}+\mathrm{i}^{2}(\mathrm{i}-1)$,
$i=1,2,--------, 2 n-2$
$f_{\text {adcss }}^{*}\left(v_{2 n-1+i} v_{2 n+i}\right)=(2 \mathrm{n}-1+\mathrm{i})^{2}(2 \mathrm{n}-2+\mathrm{i})+(2 \mathrm{n}+\mathrm{i})^{2}(2 \mathrm{n}+\mathrm{i}-1)$,
$i=1,2,3,-\cdots-----2 n-2$.
$f_{\text {adcss }}^{*}\left(v_{2 n-2+2 i} v_{2 n+2 i}\right)=(2 \mathrm{n}-2+2 \mathrm{i})^{2}(2 \mathrm{n}-3+2 \mathrm{i})+(2 \mathrm{n}+2 \mathrm{i})^{2}(2 \mathrm{n}+2 \mathrm{i}-1)$,
$f_{\text {adcss }}^{*}\left(v_{2 i-1} v_{2 i+1}\right) \quad=(2 \mathrm{i}+1)^{2} 2 \mathrm{i}+(2 \mathrm{i}-1)^{2}(2 \mathrm{i}-2)$
$f_{\text {adcss }}^{*}\left(v_{2 i} v_{2 i+2 n-1}\right)=(2 \mathrm{i})^{2}(2 \mathrm{i}-1)+(2 \mathrm{i}+2 \mathrm{n}-1)^{2}(2 \mathrm{i}+2 \mathrm{n}-2)$,
$f_{\text {adcss }}^{*}\left(v_{2 i-1} v_{2 i+2 n-2}\right)=(2 \mathrm{i}-1)^{2}(2 \mathrm{i}-2)+(2 \mathrm{i}+2 \mathrm{n}-2)^{2}(2 \mathrm{i}+2 \mathrm{n}-3)$,
$i=1,2,3,----n-1$.
$\mathrm{i}=1,2,--------------,-1$
$\mathrm{i}=1,2,--------------, n-1$

All edge values of $G$ are distinct, which are multiples of 2.That is the edge values of $G$ are in the form of an increasing order. Hence $T^{2}\left(T_{n}\right)$ admits adcss-labeling.

Example 2.5 ADCSS labeling of the graph $\mathrm{T}^{2}\left(\mathrm{~T}_{4}\right)$ is shown in figure (v)

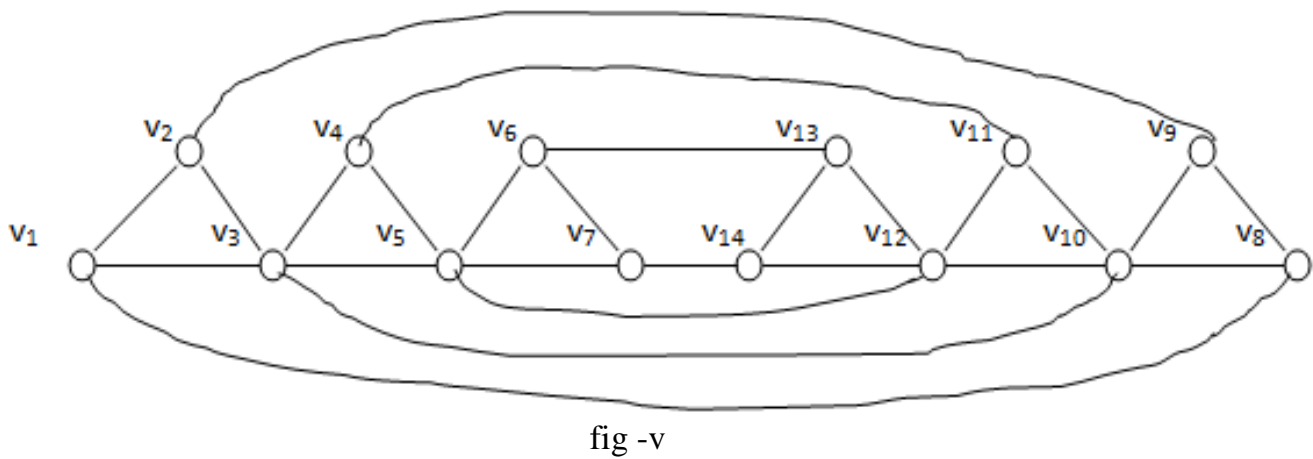

Theorem: 2.6 $\mathrm{T}^{2}\left(\mathrm{Q}_{\mathrm{n}}\right)$ admits ADCSS - labeling, where $\mathrm{Q}_{\mathrm{n}}$ is the quadrilateral snake graph.

Proof : Let $\mathrm{G}=\mathrm{T}^{2}\left(\mathrm{Q}_{\mathrm{n}}\right)$ and let $\mathrm{v}_{1}, \mathrm{v}_{2},-----------, \mathrm{v}_{6 \mathrm{n}-4}$ are the vertices of $\mathrm{G}$.

Here $|\mathrm{V}(\mathrm{G})|=6 \mathrm{n}-4$ and $\quad|\mathrm{E}(\mathrm{G})|=11 \mathrm{n}-10$

Define a function $\mathrm{f}: \mathrm{V} \rightarrow\{1,2,3,-------, 6 \mathrm{n}-4\}$ by

$f\left(v_{i}\right)=i, i=1,2,-----, 6 n-4$.

For the vertex labeling $\mathrm{f}$, the induced edge labeling $f_{\text {adcss }}^{*}$ is defined as follows
$f_{\text {adcss }}^{*}\left(v_{i} v_{i+1}\right)$
$=(\mathrm{i}+1)^{2} \mathrm{i}+\mathrm{i}^{2}(\mathrm{i}-1)$
$f_{\text {adcss }}^{*}\left(v_{3 n-2+i} v_{3 n-1+i}\right)$
$=(3 \mathrm{n}-2+\mathrm{i})^{2}(3 \mathrm{n}-3+\mathrm{i})+(3 \mathrm{n}-1+\mathrm{i})^{2}(3 \mathrm{n}-2+\mathrm{i})$,
$f_{\text {adcss }}^{*}\left(v_{3 i-2} v_{3 i+1}\right)$
$=(3 \mathrm{i}-2)^{2}(3 \mathrm{i}-3)+(3 \mathrm{i}+1)^{2}(3 \mathrm{i})$,
$f_{\text {adcs }}^{*}\left(v_{3 n-4+3 i} v_{3 n-1+3 i}\right)=(3 \mathrm{n}-4+3 \mathrm{i})^{2}(3 \mathrm{n}-5+3 \mathrm{i})+(3 \mathrm{n}-1+3 \mathrm{i})^{2}(3 \mathrm{n}-2+3 \mathrm{i})$,
$f_{\text {adcss }}^{*}\left(v_{i} v_{3 n-2+i}\right)$
$=(3 n-2+i)^{2}(3 n-3+i)+i^{2}(i-1)$
$i=1,2,----------, 3 n-3$
$i=1,2,3,--------, 3 n-3$
$i=1,2,3,-------\cdot n-1$.
$i=1,2,----------, n-1$
$i=1,2,--------, 3 n-2$

All edge values of $G$ are distinct, which are multiples of 2.That is the edge values of $G$ are in the form of an increasing order. Hence $T^{2}\left(Q_{n}\right)$ admits adcss-labeling.

\section{References}

[1] Danuta Michalak, "On middle and Total Graphs with coarseness number equal 1". Springer Verlag Graph Theory, Lagow (1981) proceedings. Berlin Heidelberg, New York, Tokyo pp 139-150

[2] F Harary, Graph Theory, Addison-Wesley,Reading, Mass, (1972)

[3] Joseph A Gallian, A Dynamic Survey of Graph Labeling, The Electronic Journal of Combinatorics(2015), \#DS6, Pages 1-389.

[4] P.L Vihol \& P.H Shah, Difference Cordial Labeling of 2-tuple graphs of some graphs, International Journal of Mathematics and its Applications, Volume 4, Issue 2-A (2016), 111-119

[5] T K Mathew Varkey, Some Graph Theoretic Generations Associated with Graph Labeling, PhD Thesis, University of Kerala 2000

[6] Mathew Varkey T K, Sunoj B S, A Note on Absolute Difference of Cubic and Square Sum Labeling of a Class of Trees, International Journal of Scientific Engineering and Applied Science -Volume- 2, Issue- 8 ,August 2016, Pages 293-296

[7] Mathew Varkey T K, Sunoj B S, An Absolute Difference of Cubic and Square Sum Labeling of Splitting Graphs, International Journal of Computer \& Mathematical Sciences-Volume- 5,Issue-8, August 2016, Pages 16-18.

[8] Mathew Varkey T K , Sunoj B S, ADCSS Labeling of Cycle Related Graphs, International Journal of Scientific Research \& Education - Volume- 4, Issue- 8 , August 2016, Pages 5702-5705.

[9] Mathew Varkey T K, Sunoj B S, An Absolute Difference of Cubic and Square Sum Labeling of Certain Class of Graphs , International Journal of Mathematics Trends \& Technology, Volume- 36, Number 1 ,August 2016, Pages 77-79

[10] Mathew Varkey T K, Sunoj B S, Some New Results on Absolute Difference of Cubic and Square Sum Labeling of a Class of Graphs, International Journal of Science \& Research, Volume- 5, Issue- 8 ,August 2016, Pages 1465-1467.

[11] Mathew Varkey T K, Sunoj B S, ADCSS -Labeling of Product Related Graphs, International Journal of Mathematics And its Applications Volume- 4, Issue- 2B ,August 2016, Pages 145-149. 